\title{
Learning and Personal Development within the Public Sector by a Cognitive Narrative Cultural Approach
}

\author{
Theresia Olsson Neve \\ Department of Business Studies and Information Systems, \\ Mälardalen University College \\ P.O. Box 883, S-721 23 Västerås, Sweden \\ theresia.neve@mah.se
}

\begin{abstract}
Many organisations suffer from "illness symptoms" because of high pressure and fast changing environments. There is no time for reflexion and perspective making, and learning within organisations falls short. However, if we cannot change the organisations outer pressure we must oppose the problem from inside, and it is assumed here that the narrative dialogue approach is one way to approach the problem for the employees within organisations. A 'Learning and Personal Development' Instrument has been developed in order to increase the individual's capability to describe his/her own situation within organisations. This instrument is based on ideas from the cognitive narrative area and the Socratic Question Technique. Interviews and seminars of a prototypical nature have been conducted within the health care and at universities in Sweden. The empirical results are positive for eliciting knowledge.
\end{abstract}

\section{Introduction}

Our society is characterised by a global economy, it favours immaterial things (ideas, information and relations), and it is highly connected. The interactive computer nets are growing exponentially and gives the communication new appearances and channels, and the capitalism has experienced a fundamental restructuring characterised by: more flexible management; decentralisation and network cooperation, both inside and between companies; reinforcement of the power of the capital; increased individualisation and diversification of the work conditions; govern interventions to selectively deregulate the markets and abolish the welfare states; and escalated global economic concurrence, because of geographically and cultural differentiated environments (Castells, 1996). This fast and changeable nature will affect a significant part of our society. Almost no individual, no operation, no part of the public or private sector will be uninfluenced. An overall disturbing trend is that stress symptoms among individuals in all different groupings become more ordinary.

The public sector is often responsible (according to the law) to supply the inhabitants in the society with health care, water, electricity, etc. But, if the individuals in the society, that are dependent on the quality of the service in the public sector (for example patients in the primary care), not obtain the care they need, the society will have "illness symptoms" which will be very costly in the end. It is a well-

The original version of this chapter was revised: The copyright line was incorrect. This has been corrected. The Erratum to this chapter is available at DOI: 10.1007/978-3-540-44836-5_33

M.A. Wimmer (Ed.): KMGov 2003, LNAI 2645, pp. 219-229, 2003.

(C) Springer-Verlag Berlin Heidelberg 2003 
known problem that, for example, the health care suffers from scarce resources, high pressure, sick reporting, etc.

How can we prevent and manage this "illness symptoms" within organisations in the society? If an organisation is characterised by these problems but has this societal responsibility, how can we prevent it from falling apart?

One way to approach the problem is to focus on the dialogue and motivation for the employees within organisations (if we cannot change the organisations outer pressure, we must oppose the problem from inside). It is the individual's motivation, engagement, and ability to communicate knowledge and experiences to others that underlies the possibility for the individual (and especially the whole organisation) to learn, and learning is often a sign of mental health. The dialogue helps the employees to narrate, construct and validate their own and each other's experiences.

A 'Learning and Personal Development' (LPD) instrument has been developed in order to increase the individual's capability to describe his/her own situation within organisations. Interviews and seminars of a prototypical nature have been conducted within health care and at universities in Sweden. The method has similarities with Yin's (1994) description of explanation-building, when analysing the data. The important characteristics for explanation-building are that the final explanation is a result of a series of iterations. Each interview started with questions worked up from theory and earlier practices. After each interview, the questions were evaluated in consultation with the respondent according to pre-defined evaluation criteria. It was important that the questions should teach the individual something about him/her self. It was also important that some of the answers were suited for being stored in a database. Thereafter, the questions were redesigned, and the procedure reinitiated.

The Socratic Question Technique, with its deductive and inductive reasoning, has been used as a framework for the research. This technique is believed to motivate the individual to interact with other individuals in order to contribute with knowledge, receive feedback, and receive new knowledge about him/her self and his/her colleagues. Cognitive psychotherapy frequently uses the Socratic question technique in the therapy-session and we find it interesting to make reference to the psychiatrist Carlo Perris and his definition of knowledge-growth: knowledge-growth (learning) is accomplished when "...a cognitive/emotional reconstructuring of view based upon one self, upon others and the reality takes place" (1989, p. 2112). The purpose of the Socratic question technique is to activate individuals and to encourage reflection and critical thinking; this is assumed to contribute to learning and personal development.

\section{Knowledge Elicitation}

The purpose of our research is to improve learning (Blackler, 1995, for example, is talking about encultured knowledge, which refers to the process of achieved understandings) and personal development within organisations. Even thou the application area is distinguished in the following two different examples, for example, the ecological approach as described in chapter 3 are not striving for huge amounts of data (which is often the case when building expert systems) but personal unique knowledge, the knowledge elicitation process described within the expert area is quite contiguous and useful as a contrast because we believe it represents much of how knowledge is looked upon these days. Modern social science often organises itself 
around the production of cumulative knowledge, and this knowledge about the world is kept outside the world itself instead of being in contact with and changing with the world (Alvesson \& Deetz, 2000).

The procedure of capturing knowledge into an expert system is called knowledge acquisition. A knowledge engineer interacts with an expert in order to acquire, organise, and study a problem's knowledge (Durkin, 1994). The goal is to compile a body of knowledge on the problem of interest that can be encoded in the expert system.

To acquire knowledge from the expert is distinguished from the more general knowledge acquisition term and is called knowledge elicitation (ibid). This implies an interactive session between the knowledge engineer and the expert where the knowledge engineer, many times, interviews the expert. "The main vehicle for knowledge elicitation is face-to-face discussions between the expert who possesses the domain knowledge and the knowledge engineer who asks questions..." (Gonzalez \& Dankel, 1993, p. 349) Case studies may also be used where the knowledge engineer study the expert when he or she is solving a problem.

\section{The Knowledge Elicitation Cycle}

Durkin (1994) explains the sequence of the knowledge elicitation cycle as to: (1) collect (an iterative style of collecting the information), (2) interpret (this involves a review of the collected information and the identification of key pieces of knowledge), (3) analyse (the key pieces of knowledge uncovered will provide insight into forming theories on the organisation of the knowledge and problem-solving strategies), and (4) design (now new understanding of the problem that can aid further investigations should have been formed).

\section{Direct and Indirect Questions, Probes and Prompts}

In the interview direct questions and/or indirect questions may be used. A direct question seeks answers that have a limited number of responses, for example: "What is the value of...?" Indirect questions are exploratory in nature and allow the expert to answer in a more independent way. Probes are also used in order to provide further information on the issue, for example: "Can you explain...?", "Can you discuss...?" etc. Prompts are questions intended to direct the interview in some direction. It has usually the form: "Can you discuss...?" or "Can we return to...?"

\section{The Funnel Sequence}

The funnel sequence is recommended in order to enhance effectiveness of these questions. This technique addresses a particular topic by first asking general questions to then move to more specific questions (figure 1, next page):

\section{Knowledge Elicitation from an Ecological Perspective}

An ecological approach according to the knowledge elicitation process is here defined as something that implies the importance of studying individual's actions on the basis of interpretations of motives and intentions, social norms, feelings, plans, and mutual undertaking. Castells (1997) defines the concept of ecology as follows: "By ecology, in my sociological approach, I understand a set of beliefs, theories, and projects that 
consider humankind as a component of a broader ecosystem and wish to maintain the system's balance in a dynamic, evolutionary perspective" (p. 113). We believe an individual's knowledge must be studied in the light of the individual's subjective world - i.e. individuals' actions can only be studied by interpreting their subjective contents of meaning. Here in this section, the main methodological difference between the presented approach in chapter 2 and the ecological approach will be described.

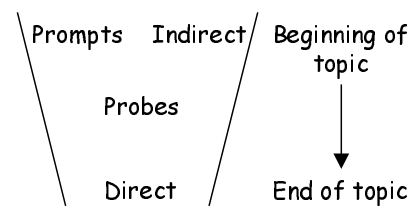

Fig. 1. Funnel Sequencing Technique (adapted from Durkin, 1994)

The Funnel Sequence in chapter 2 is described as a general-to-specific approach for eliciting knowledge and uses the types of questions introduced in the last few sections. Prompts and indirect questions are used to obtain a broad description of the topic. These are followed by probe questions in order to direct the interview toward the more detailed issues.

The ecological perspective has in general the same entrance. However, it starts with a more specific question (on the basis of a specific purpose). This question is then dealt with in an iterative manner (by using probe questions) and finally a specific knowledge description is received. What is added to the sequence in the ecological approach is a dimension where the subjective part of the individual are coped with by asking questions about his/her central references, by letting the respondent make comparisons with other individuals procedures, and raise unspoken questions the individual have up to an organisational level. Figure 2, next page, models the idea:

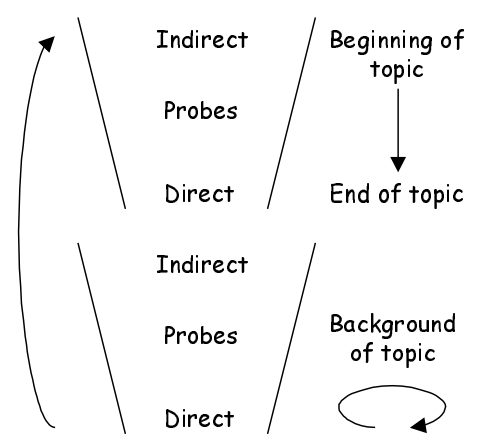

Fig. 2. The Funnel Sequence in a Broader Perspective

The human being is seen in this paper as a creature that performs actions deliberately, and that action is part of a complex system of actions with some kind of specific goals, purposes, tasks, or functions. Molander (1996) raises the question: "What constitute an actions identity?" Immediately he answers, "The identity is connected to the question why something is done" (the reasons the actor can give). This makes it extremely important to receive knowledge about the background of the topic. 


\subsection{Perspective Making and Perspective Taking}

In the activities that constitute our form of life is question-answer one of the links that holds together the mutual understanding of what we do (Molander, 1996). Answers and opposite questions contributes to verification, modification and sometimes to a deepening of our comprehension of what others and we are doing. For example, Boland and Tenkasi (1995) are arguing for the importance of being able to create strong perspectives within a community, as well as the ability to take other perspectives into account. This improves the individual's capability to understand and influence the situation/environment in which he/she is a part.

By interacting with others in dialogues, we are aided in formulating thoughts and tacit skills (i.e. implicit personal knowledge difficult to articulate in language), as well as forced (or have the opportunity) to structure our thoughts and mental models and express them in an understandable way (in words and/or in images) for others. When we narrate our experience we also construct and validate the self, and in an externalisation-internalisation situation of knowledge, we learn (1) when we talk (when we express ourselves and/or explain something), (2) when we listen to others, (3) when we give feedback to others, and/or (4) when receiving it.

Before two individuals start to interact with each other, they have their earlier assumptions, experiences, values, etc. When a person asks another person something, this person replies and the conversation begins. They give each other feedback and their dialogue results hopefully in new understandings and knowledge for them both. When the individual articulate and externalise something he/she becomes at the same time aware of his/her personal knowledge that he/she have but earlier have taken for granted or have had implicit.

\subsection{The Cognitive Narrative Dialogue}

A dialogue is a conversation between two or more individuals with the purpose to help the individual to reflect and to widen his/her boundaries. "[It] is a dialectical movement between examples and different ways to talk about these examples to put them in a greater wholeness. The goal is not to break down the concepts in its "parts", but to try them in usage in different contexts" (Molander, 1996, p. 208, authors own translation).

The dialogue is a fundamental model for knowledge creation. The psychiatrist Carlo Perris' (1989) definition of knowledge creation is useful here: "[It is] the process which leads to a reach beyond the current state of clarity, competence and comprehension, or, in other words, that a cognitive/emotional reconstructuring of view based upon him/her self, upon others and the reality takes place" (p. 2112, authors own translation). An interpretation should occur in the knowledge process which leads to a corresponding image, both useful for the observer and the actor.

Bruner (1986) differs between two distinct modes of cognition, the paradigmatic mode and the narrative mode. The paradigmatic mode tries to establish reality by formal and empirical proof, and the narrative mode gives the ability to see possible formal connections before one is able to prove them in any formal way. It is more about verisimilitude than truth, and cognitive psychotherapy, with its focus on the Socratic question technique, falls within its scope. 


\subsubsection{The Socratic Question Technique}

Many authors make references to Socrates when they want to discuss the "true" search for knowledge (see for example Selling, 1984; Perris, 1989; d'Elia, 1992; Hoppe Jakobsson, 1992; Molander, 1996; and Svenneby, 2002). Socrates represents some kind of symbol for the unbribable search for truth by continuously asking critical questions (Molander, 1996).

The goal with the Socratic question technique is to find knowledge and insight that the participants already have, even if they do not know that they have it. Questions, answers and reflection should make non-reflective knowledge and insight available. That this goal never in full is achieved is an important aspect of the dialogue. (ibid)

Molander (ibid) explains the characteristics in the Socratic Method as follows:

- The dialogue has a concrete situation as a presupposition

- Socrates behaves as if he has no knowledge in that way that he knows the answer of the central question

- Socrates turns to another person who think that he/she knows

- Socrates just want to learn and is a true knowledge searcher who "does not know for sure"

- However, Socrates does not pretend to be totally ignorant. This means that he has a will to learn; he listens, observes, ask questions, and so on. He is not a passive listener.

- Socrates questions uncover ignorance

- It is important that the dialogue partner will realise this ignorance by him/her self

The "resistance" an individual meets in dialogue is of great importance. As in cognitive psychotherapy, it is here assumed that the right questions will help individuals to relieve their knowledge (Perris, 1989). In general, questions should promote individual awareness and mutual comprehension and not lock the individual, not mislead, or give him or her incorrect associations.

Cognitive psychotherapy is a learning process in which the goal for the individual is to receive new knowledge about him/her self. It is an active process (where the therapist not only should listen to the patient passively with empathy and express an opinion "at an appropriate occasion"), directive process (the individuals' mental structures continually develop when his/her knowledge about him/her self and the world around grows), and humanistic process (if humans are regarded as, so called, "pilots", you see the individual as capable to take control over his/her behaviour and situations he/she confronts). This approach is characterised by collaborative empiricism, where two individuals cooperate in an investigating way (ibid). They collect facts and presents hypotheses, to thereafter analyse their acceptability; if they should remain or rejected and replaced. Note, it is important that the investigator not becomes the central character in the interview, which too often is the case (Fisher \& Geiselman, 1992).

The statement in chapter 3 , that the human being is seen as a creature that performs actions deliberately, and that action is part of a complex system of actions with some kind of specific goals, purposes, tasks, or functions, makes the cognitive theoretically traditions collected knowledge of how learning and change is possible as an enabler to increase the understanding of knowledge and actions in the knowledge elicitation process. 


\subsubsection{Cognitive Techniques}

Cognitive techniques are used to change individuals' fundamental assumptions - i.e. preconceived hypotheses. They are used to make a map of thoughts of patterns, capture traps in thought, and find alternative ways of thinking.

Examples of specific techniques are (Freeman et al., 1994; Malm, 1992; Wistedt, 1997; Hoppe Jacobsson, 1994; Perris et al., 1988):

- Clarify concepts. To have an effective and fruitful dialogue, concepts and formulations must be clarified. The word "satisfied", for example, might be interpreted in a number of different ways. Questions like: "What do you mean by...?", "What does it mean to you...?", "In what way does it affect you...?", etc., guides the respondent in the right direction.

- Investigate sources of evidence. An effective way to question the description is to investigate to what extent the description are confirmed or proved to the opposite or if it eventually exist some other interpretations. Questions like: "Could you give me an example...?", "How do you know that...?", "Has someone said...?" etc., helps to investigate the source.

- Reattribute. To reattribute is to rewrite the situation. Examples of questions are: "Could it be interpreted in another way?", "What do you think I think?", "How do you think others see it?" etc.

- Investigate alternatives. To investigate alternatives is to try to have a perspective of the situation, questions like: "Is this the only way?", "How is this done by other individuals?", Could this be done in some other way?", could be used.

- Cognitive repetition. Cognitive repetition is to verify that there is a correspondence in the dialogue. Questions like: "Have I understood it right...?", "Could we sum up?", "What have we been talking about?" etc., are useful to ask.

A concluding remark: the cognitive approach may be perceived like "common sense". There could also at times be difficult to perceive the difference to more "traditional" ways of, for example, interviewing. However, the techniques above should be used in accordance with the whole cognitive therapeutically frame (the whole culture): structure, collaboration, respect, focus, feed-back, open-mindness (for perspective making and perspective taking), asking right questions in order to 'deliver' knowledge, etc., this to strengthen individuals at a deeper level.

\subsection{The Ecological Knowledge Elicitation Process}

The main purpose with the project is to develop the overall process around the management of knowledge within organisations (an Ecological Knowledge Management System): from (1) management and organisational mobilisation (with the important activities to define the knowledge management strategy, to define key performance indicators that will measure existing knowledge-exchanging activities, appoint knowledge managers in the organisation, etc.) to (2) identifying knowledgekey individuals (it is important to identify knowledgeable and interesting individuals who have a crucial importance of the organisations future development and who have the capacity of helping others to relieve their knowledge), to (3) generate the knowledge, and to (4) package, spread and reuse it. These parts will not be presented here in this paper when the specific 'Learning and Personal Development' (LPD) Instrument is in focus. However, three questions must be answered before the 
knowledge-eliciting activities starts: what is the goal with the knowledge-elicitation activities?, what questions should these activities answer in general, and who will be the specific user of the externalised knowledge? (Blair, 1984).

\subsubsection{The 'Learning and Personal Development' Instrument Outlined}

The extended knowledge elicitation process is described from a "knowledge-inaction" perspective. An individual's action is always part of a wider context, and it must always be understood in this context (Molander, 1996). A visual description of the procedure is presented below (figure 3). Two major streams may be recognised in the process: one knowledge-generating part (phase 1-4), and one part for developing the individual (phase 3-6).

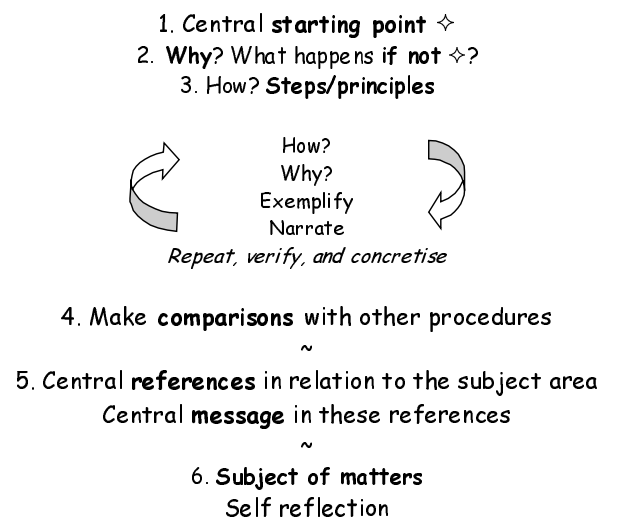

Fig. 3. The Ecological Knowledge Elicitation Process

Most important of all when asking questions according to a cognitive (psychotherapeutically) manner is that the opening question(s) should be as wide as possible and the questions in general should be value-neutral.

\section{Step 1}

(Phase 1) The procedure begins with a central starting point, for example with the question, "how do you look at your work situation?" The opening phase should be general enough to not mislead the individual in an incorrect direction, and specific enough to attract attention for him/her.

Step 2

(Phase 2) Thereafter, to verify that the topic is of significance and worth to handle, one should question what happens if not. This phase should be characterised by critical thinking and de-familiarisation, i.e. how to think and act dialectically and how to turn the well-known into the unusual (Alvesson \& Deetz, 2000).

Step 3

(Phase 3) As a third phase, the issue will be dealt with in an iterative manner in different steps and/or principles. In general, the interviewer continuously repeats, verifies, and concretises the respondent's description by asking how and why, and 
requesting him/her to exemplify and narrate the issue - "tell me how you perform your tasks in different steps", "how?", "could you exemplify?", "in what way?", "do you mean that...?", "is it correct that...?”, "have I understood you right when...?" After this sequence some form of explicit knowledge description should be available.

The following example illustrates the procedure described above: A respondent were asked to explain how she proceeded in a particular matter, and from the beginning she found it somewhat ridiculous to discuss the issue (she thought this was widely known in the organisation). However, during the session a structure started to evolve, and finally when she saw her story in a formalised representation, she understood its value for others.

Ambrosini and Bowman (2001) have developed a similar method - a mapping process, based on cognitive and causal maps, semi-structured interviews, and metaphors. The mapping process (with focus on a special issue) raises questions like; 'What causes A to happen?', 'How does A happen?', 'Could you tell me an example about B?', and 'Could you narrate a story about the occurrence of C?' Since tacit knowledge has a cognitive dimension, is practical, context specific, and difficult to formalise (ibid), this approach will help individuals articulate the tacit and often taken for granted knowledge.

\section{Step 4}

(Phase 4) Fourthly, reflection and comparisons with others behaviour or procedures will take place. A good question to ask is, "do you think your way of doing this is different from how others do it?" (However, the word 'different' must not be parsed as negative).

The technique of Repertory Grids might be used (Kelly, 1963). These consist of a chart, in which "elements" usually placed in columns, are rated by adjectival phrases or simple adjectives known as "constructs" set in rows. For example, to the constructs 'trust' and 'honesty', a nurse may have the following directional relationships: "nurse to patient", "patient to nurse", "nurse to colleagues", "colleagues to nurse", etc.

\section{Step 5}

(Phase 5) An individual's central references will next be sought. One could for example ask if there is someone the respondent is inspired of or influenced by in a particular matter. This gives an opportunity to start to unwind some of his/her underlying assumptions. Individuals might not share their tacit knowledge because of a risk of loosing power and competitive advantage, but by supplying ones references, the individual has the possibility to be understood, without revealing any specific valuable knowledge. The questions: "is there any central in your thinking that affects your actions when it comes to... (the discussed issue)?" tries to create an understanding to why the individual acts as he/she does.

The psychoanalyst Erich Fromm used a similar technique in his studies of the German working class. His classical question: 'Name three people, living or dead, that you admire the most, and why?', has been used to interpret the ideal and characteristics the respondent values and aspires to in order to characterise him/her self (Rendahl, 1992).

At this point in the empirical tests, when steps 1-5 had been conducted, it was observed that the discussion of other issues and extraction of knowledge (steps 1-4) from the respondent became increasingly unhindered. The interviewer had attained an 
appreciation of the respondent, and he/she in turn received assistance in revealing underlying assumptions or mental models related to the knowledge to be elicited. This helped a number of individuals to further relate their behaviour to other actions.

Step 6

(Phase 6) The last step tries to raise unspoken questions the individual have in order to lift them to an organisational level - "if you could ask you colleagues anything, what would you ask?" The respondent is also requested to reflect about the question by him/her self: "how do you do it by your self?"

To sum up, instead of searching for "the right answer", the purpose is to have the individual to describe his/her version in such a way that others understand the description (what, why and how) and have the possibility to make their own interpretation of it.

\section{Summary and Concluding Remarks}

Gaines (2003) has, in his article "Organizational Knowledge Acquisition”, a similar view as ours when discussing how to develop a model of organisational knowledge acquisition. He describes the recognition of knowledge as critical in distinguishing rational arguments from emotional ones, he explains some of the reasons of the failure of artificial intelligence, the nature of human behaviour, and so on.

Gaines continues to point out that it is better to perform actions in a way that is not 'wildly wrong' rather than to compute the 'optimum situation'. So far we agree with him. However, he continues to say that actual expertise arises naturally through positive feedback processes involved in proto-experts having greater access to learning experiences, and models the expert as the central part in the formation for interaction between the client community and professional community (consisting of case histories, theories and strategies). And here we question, is learning really promoted by this?

We believe expert-thinking, when it comes to learning, is erroneous and misleading. In a learning process one should first and foremost not talk about knowledgeable individuals as experts, but of leadership, assistance, and guidance.

For example health care is very much characterised by expert-thinking. The organisation is separated into different functions, like; physicians, nurses, assistant nurses, laboratory personnel, receptionists, almoners, therapists, physiotherapists etc., where the physicians holds the highest order of rank (this was noticed in our interviews and seminars). The level of coordination and mutual adjustment among functions are reduced with hierarchical and expert-thinking, and as a result we believe it is central to re-investigate the learning situation from another perspective. We suggest the utilisation of the culture and techniques, as found within the cognitive narrative mode (i.e. cognitive psychotherapy), enables a passable way to start to deal with this problem. Besides, as have been discussed in the paper, the approach is more concerned about learning as a complex process involving skills like mental mapping, use of intuition and imagination, and problem solving, instead of a view of learning as more de-humanised. 


\section{References}

1. Alvesson, M. \& Deetz, S. (2000) Doing Critical Management Research. SAGE Publications.

2. Ambrosini, V. \& Bowman, C. (2001) "Tacit Knowledge: Some Suggestions for Operationalization”. Journal of Management Studies, 38:6, pp. 811-829, September.

3. Blackler, F. (1995) "Knowledge, Knowledge Work and Organizations: An Overview and Interpretation". Organization Studies, 16/6, pp. 1021-1046.

4. Blair, D. C. (1984) "The Management of Information: Basic Distinctions", Sloan Management Review, Fall.

5. Boland, R. J. \& Tenkasi, R. V. (1995) "Perspective Making and Perspective Taking in Communities of Knowing", Organization Science, Vol. 6, No. 4, pp. 350-372, JulyAugust.

6. Bruner, J. (1986) Actual Minds, Possible Words. Harvard University Press.

7. Castells, M. (1997) The Information Age: Economy, Society and Culture, Vol 2: The Power of Identity. Blackwell.

8. Castells, M. (1996) Informationsåldern: ekonomi, samhälle och kultur Bd 1: Nätverkssamhällets framväxt. Daidalos.

9. d'Elia, G. (1992) "Kognitiv terapi - inlärningsprocess som förändrar dysfunktionella tankemönster. Läkartidningen, Vol, 89, No, 48.

10. Durkin, J. (1994) Expert Systems - Design and Development, Prentice Hall.

11. Fisher, R. P., \& Geiselman, R. E. (1992) Memory-Enhancing Techniques for Investigative Interviewing. Charles $\mathrm{C}$ Thomas, Springfield, Illinois, USA.

12. Freeman, A., Pretzer, J, Fleming, B. \& Simon, K. M. (1994) Kognitiv psykoterapi i Klinisk tillämpning, Pilgrim Press.

13. Gaines, B. R. (2003) "Organizational Knowledge Acquisition”, in Holsapple, C. W. [ed] (2003) Handbook on Knowledge Management. Berlin: Springer.

14. Gonzalez, A. J. \& Dankel, D. D. (1993) The Engineering of Knowledge-Based Systems Theory and Practice, Prentice Hall.

15. Hoppe Jacobsson, U. (1992) "Hur kan vi förstå alkoholisters handlande?" PhD. Thesis, Department of Education, Stockholm University.

16. Hoppe Jacobsson, U. (1994) "Den sokratiska dialogen", Compendium from Pro Vobis. Unpublished.

17. Kelly, G. A. (1963) A Theory of Personality: the Psychology of Personal Constructs. Norton, New York.

18. Malm, K. (1992) "Frågebank”, Kognitivt Center, Danderyds Sjukhus. Unpublished.

19. Molander, B. (1996) Kunskap i handling, Daidalos.

20. Perris, C. (1989) "Det psykoterapeutiska arbetet en lärprocess som syftar till personlig kunskapstillväxt”. Läkartidningen. Vol. 86, No. 22, pp. 2112-15.

21. Perris, C., Blackburn, IM. \& Perris, H. (1988), The Theory and Practice of Cognitive Psychotherapy. Berlin; New York: Springer-Verlag.

22. Rendahl, J-E. (1992) Arbetets drivkrafter: existentiellt värde och auktoritetsorientering: två dimensioner som belyser arbetets mening för de anställda $i$ kriminalvården. PhD. Thesis, Lund University, Sweden.

23. Selling, M. (1984) Om tänkesättet Sokrates, Own Publishing House, Lund, Sweden.

24. Svenneby, E. (2002) "Den sokratiske dialog og motstandermetoden", in Om samtal - en nordisk antologi, Holm, U. M. [ed].

25. Wistedt, B (1997) "Kompendium kognitiv psykoterapi”, Psykiatriska kliniken, Danderyds Sjukhus

26. Yin, R. K. (1994) Case Study Research: Design and Methods. SAGE Publications, Inc. 